\title{
Cosmovisão Cristã na Didática Magna de Comenius
}

\section{Christian Worldview in Didactica Magna of Comenius}

Resumo: Este estudo, que se insere no campo da história das ideias pedagógicas, analisa o pensamento do educador João Amós Comenius (1592-1670) na sua obra clássica Didática Magna: a arte de ensinar tudo a todos, publicada em 1657. O objetivo é conhecer as propostas educacionais do autor, considerando o contexto em que foram elaboradas e a visão de mundo que as nortearam. O referencial teórico para a referida análise é a sociologia da religião de Max Weber (2004), que aponta o impacto das convicções religiosas na ação social dos indivíduos. Analisa, neste caso, o impacto do "ascetismo intramundano" da ética protestante nas elaborações de Comenius. Trata-se de uma pesquisa documental, tendo como fonte principal a obra Didática Magna. O estudo possibilita uma compreensão das propostas educacionais de Comenius, articuladas ao espírito do século XVII e suas contribuições para a consolidação da ciência moderna.

Palavras-chave: Cosmovisão Cristã. Didática Magna. Comenius.

Abstract: This study, which is inserted in the field of the history of pedagogical ideas, analyzes the thought of the educator João Amós Comenius (1592-1670) in his classic work Didática Magna: the art of teaching everything to everyone, published in 1657. The objective is to know the author's educational proposals, considering the context in which they were elaborated and the worldview that guided them. The theoretical framework for this analysis is the sociology of religion by Max Weber (2004), which points out the impact of religious beliefs on the social action of individuals. In this case, it analyzes the impact of "intramundane asceticism" of Protestant ethics in Comenius' elaborations. It is a documentary research, having as main source the work Didática Magna. The study provides an understanding of Comenius' educational proposals, articulated with the spirit of the 17 th century and his contributions to the consolidation of modern science.

Keywords: Christian Worldview. Magna Didactics. Comenius.

\section{Introdução}

Considerando que "em grande parte da literatura especializada, João Amós Comenius é lembrado como o grande precursor da Didática como campo de estudo, acrescido de métodos, etapas e sistematização do trabalho docente" (PEREIRA, 2016, p. 106), este trabalho, que se insere no campo da história das ideias pedagógicas, analisa o pensamento de Comenius, considerando-o clássico, atendo-se à sua obra mais conhecida, a Didática Magna: 
a arte de ensinar tudo a todos. A relevância do estudo dos clássicos do pensamento educacional para a compreensão das teorias e práticas educativas, especialmente no processo de formação de professores (Cf. ALVES; WALDOW, 2009; GASPARIN, 1997; PARANÁ, 2016) e de pesquisadores (Cf. TEIXEIRA; ZANOTELLI; CARRIERI, 2014), tem sido amplamente reconhecida, por serem eles referência para a construção de paradigmas. Quanto à história das ideias pedagógicas, entendidas por Saviani (2013) como “a forma que se encarnam no movimento real da educação, orientando e, mais do que isso, constituindo a própria substância da prática educativa", o objetivo é fornecer possibilidades de análise de um aspecto da obra em estudo, que servirá de base para as suas propostas referentes ao processo de ensino e aprendizagem, no contexto específico, e suas influências mais amplas. Saviani (2013, p. 21) justifica o estudo da história das ideias pedagógicas:

considerando-se a inerente historicidade do fenômeno educativo, o conhecimento desse fenômeno em seu desenvolvimento históricoobjetivo fornece elementos da maior relevância não apenas para entender a educação, mas também para realizá-la praticamente [...] ajuda a tomar consciência da maneira como se articulam na prática pedagógica cotidiana as ideias educacionais que circulam em nosso meio. Com isso, criam-se as condições para introduzir maior coerência e consistência na ação educativa.

Gadotti (2002) também ressalta a relevância do estudo da história das ideias pedagógicas, apontando para os seus objetivos, que vão além do mero conhecimento do que "os filósofos disseram a respeito da educação": Mais do que possibilitar um conhecimento teórico sobre a educação, tal estudo forma em nós, que somos educadores, uma postura que permeia toda a prática pedagógica. Essa postura nos introduz a uma atitude de reflexão radical diante dos problemas educacionais, levando-nos a tratá-los de maneira séria e atenta.

Esses pressupostos norteiam o presente trabalho sobre o pensamento de Comenius, considerado por Cambi (1999, p. 281) “o maior pedagogo do século XVII”. A obra é, por demais, abrangente, possibilitando abordagens de diversos temas. Neste texto, o objetivo é problematizar a cosmovisão cristã, na Didática Magna. Weber (2004) será referência, considerando o seu conceito de "ascetismo intramundano" nessas propostas educacionais.

\section{A Trajetória pessoal e intelectual de João Amós Comenius}

João Amós Comenius nasceu no dia 28 de março de 1592, em Nivcnice2, na Morávia, Boêmia, atual República Tcheca (GASPARIN, 2011, p.18; LOPES, 2006, p. 95) em uma família religiosa pertencente à comunidade dos “Irmãos Morávios", iniciada na Boêmia, no 
século XV.3 O seu pai faleceu em 1602 e, em 1604, a sua mãe e as duas irmãs; tendo ele ficado aos cuidados de uma tia. Nessa época frequentou a escola elementar da União dos Irmãos, que exerceu grande influência na sua formação. Viveu em um contexto de guerras, ocasionando o seu afastamento da escola por quatro anos, o que, segundo o próprio Comenius, trouxe-lhe prejuízos, restringindo-lhe oportunidades (Cf. LOPES, 2006, p. 96). Essa experiência pode ser justificativa para a sua intensa busca de harmonização das pessoas, como analisado por Gasparin (2011). A sua infância conturbada, exigindo uma educação prática, voltada para a sobrevivência, tem sido associada a sua ênfase sobre a união entre o conhecimento teórico e sua aplicação prática: "O desenvolvimento das faculdades e o domínio das coisas pela ação" (LOPES, 2006, p. 97). Silva e Saldanha (2017, p. 16), destacam a experiência de Comenius na família que o abrigou após a morte dos seus pais e suas irmãs: "Lá sob a tutela de seu tio, um artesão moleiro, faltou-lhe a educação formal, contudo, Comenius pode conhecer a arte de ofício na qual praticava seu tio, iniciando-o nas atividades manuais". Em 1608, aos 16 anos, matriculou-se na escola de latim de Prerov, onde teve acesso às artes liberais: gramática, retórica e a dialética. Essa escola, segundo Lopes (2006), havia passado por uma reforma sob a influência do educador Carlos Zerotín, tendo como parâmetro o modelo da educação escolar calvinista, oriundo de Genebra, na Suíça. A ideia de Carlos Zerotín era substituir o modelo educacional jesuíta por um modelo que se adaptasse mais ao espírito dos alunos, sendo menos literária e mais prática, não se limitando à memorização de textos ininteligíveis atribuído ao sistema jesuítico (Cf. LOPES, 2006). Nessa escola, adquiriu conhecimento das artes de impressão e encadernação, o que pode terlhe reforçado o gosto pelos livros. Em 1611, por destacar-se nos estudos, foi apoiado por Carlos Zerotín para estudar na universidade de Herbon, Alemanha, onde cursou teologia e teve influência do pensamento de Francis Bacon. Em 1613, na Universidade de Heidelberg, Holanda, defendeu a sua tese teológica, aprofundou-se nos estudos, usufruindo da privilegiada biblioteca ali existente. Em Praga iniciou o seu magistério, e foi reitor da escola e Prerov em 1614. Em 1616, foi ordenado pastor da comunidade dos Irmãos Morávios. Em 1618, assumiu a direção da escola de Fulnek. Os anos que se seguiram foram de intensos conflitos, gerando violência e terror por motivos religiosos. Covelo (apud LOPES, 2013, p. 238) cita Comenius:

Trinta e seis mil famílias saíram da Boêmia e da Morávia, fiéis às suas convicções. A população checa diminui oitenta por cento. A guerra causa horror em Comenius: Quantos seres humanos mortos - deplora. Quantos presos! A quantos ceifou a fome, a peste, o frio, a amargura, o medo, o horror! Quantos templos foram tomados! Quantos sacerdotes banidos! Quantas famílias empobrecidas, das classes elevadas, como das classes 
baixas. E quantos se desviaram coagidos pela prisão e pelas torturas, ou vítimas de enganos astutos. E não há neste mundo esperança alguma de melhoras [...]. Terminam as guerras, mas outras se seguem e a peste nada nos deixou senão algumas cidades despovoadas. Mas que digo, deixou-as? Ainda as continua a devorar. Em tudo há uma carestia nunca vista; impostos e tributos superiores às possibilidades humanas pesam sobre nós, e não só as autoridades como também a soldadesca saqueiam-nos à vontade e, o que é pior, sobre corpos e almas imperam a tirania e a violência.

Nesse período, Comenius foi preso, depois teve que refugiar-se em lugares diversos, perdeu os seus bens, inclusive livros e manuscritos. No exílio, tornou-se pastor dos refugiados e, em 1623, escreveu a obra O labirinto do mundo e o paraíso do coração, dedicada a Carlos Zerotín, seu mestre. Essa obra se tornou importante na literatura tcheca e serviu de consolo para os sobreviventes das guerras. Outra obra com o mesmo objetivo foi A prensa de Deus, de 1624, dedicada a um nobre morávio que se encontrava no exílio (LOPES, 2006, p. 116). Refugiado em Leszno, na Polônia, Comenius retoma a sua dupla atividade de educador: professor e pastor. Lecionou no colégio da cidade, tornando-se seu reitor em 1636, quando “foi encarregado de supervisionar a educação na Colônia dos Irmãos Morávios, e desenvolveu ampla atividade cultural, introduzindo o teatro como recurso didático" (LOPES, 2006, p.119). Nessa década de 1630, escreveu as suas principais obras relacionadas à educação, desenvolvendo a sua pansofia, predominante na Didática Magna. Nutria a esperança de que, por meio da educação, a paz pudesse ser estabelecida.

Nesse sentido, Cambi (1999, p. 285) afirma:

Comenius vive com grande intensidade, participando das desventuras políticas e religiosas do seu povo. Os dolorosos acontecimentos ligados ao desenvolvimento da guerra, até a ruína definitiva de qualquer ilusão política e religiosa dos Irmãos Morávios, não enfraquecem o seu temperamento batalhador, estimulando-o a conceber um projeto de ordem e pacificação universal que encontra na educação o seu instrumento privilegiado e na sistematização definitiva do saber a sua condição essencial.

Em 1641, com as concepções pansóficas, Comenius impressionou os ingleses, motivando um convite para praticá-las na Universidade de Oxford. Mas a sua permanência ali durou apenas um ano, considerando agitações políticas internas relacionadas aos conflitos com a Irlanda. Foi para a Suécia, onde dirigiu a reforma escolar. Produziu, nesse contexto, uma obra sobre estudos comparativos das línguas e arte de tradução, sempre enfatizando a educação como meio para se alcançar a paz entre as nações. Retornou a Leszno, na Polônia, em 1648, sendo curta sua permanência ali. Após esse período, assume a direção de escola na 


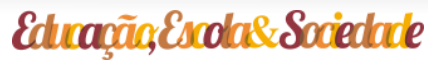

Hungria, em 1650, onde permanece por 4 anos; retornando a Leszno, onde, em 1655, em virtude dos conflitos políticos que levaram ao incêndio da cidade, Comenius experimenta mais uma turbulência, perdendo novamente os seus bens, a sua biblioteca e manuscritos. Completamente pobre e enfermo, consegue refúgio em Amsterdam, Holanda, onde goza de grande prestígio e, em 1657, edita a Didática Magna. Faleceu no dia 15 de novembro de 1670 (Cf. LOPES, 2006, p. 96-131). Mesmo com uma trajetória pessoal turbulenta, Comenius escreveu mais de 200 obras, sendo consideradas as principais: O labirinto do mundo (1623); Didactica tcheca (1627); Guia da escola materna (1630); Porta aberta das línguas (1631); Didactica Magna, versão latina da Didactica tcheca, (1631); Novíssimo método das línguas (1647); O mundo ilustrado (1651); Opera didactica omnia ab anno (1657); Consulta universal sobre o melhoramento dos negócios humanos (1657); O anjo da paz (1667); A única coisa necessária (1668). A sua abordagem, fundamentada em pressupostos cristãos, explica-se pelo contexto europeu dos séculos XV ao XVII. O “teocentrismo" medieval, sujeito à interpretação do Clero de Roma, fora superado pela valorização do indivíduo como ser inteligente, criado à imagem e semelhança de Deus, responsável pelo exame e transformação da natureza para o bem, sendo essa uma responsabilidade outorgada pelo próprio Criador. Essa nova forma de teocentrismo contribuiu, segundo Hoykaas (1988) e Pearcey e Thaxton (2005), para o desenvolvimento da ciência moderna.

\section{A obra "Didática Magna: a arte de ensinar tudo a todos"}

A produção bibliográfica de Comenius foi bastante extensa e abordou uma diversidade de temas. Dentre as suas obras, entretanto, destacou-se a Didática Magna, texto que lhe proporcionou o reconhecimento como "pai da didática moderna” (Cf. GONTIJO, 2016, p. 10). Embora tenha sido escrita na Boêmia, entre 1628 a 1632, foi publicada pela primeira vez em Amsterdam, Holanda, em 1657. O texto originalmente escrito, tendo como objetivo dialogar com a realidade local, ao ser traduzida para o Latim, sofreu algumas modificações, considerando a ampliação do seu alcance. A versão inicial havia sido dedicada à "nação Boêmia". Ampliada a abrangência dos seus objetivos, a obra passou a ser dedicada "a todos os que presidem os assuntos humanos, aos ministros de Estado, aos pastores das Igrejas, aos diretores das escolas, aos pais e aos preceptores de jovens”. Essa dedicatória sinaliza a compreensão de Comenius sobre o caráter amplo da educação e os diversos espaços onde ela é realizada: na família, no Estado, na Igreja (Instituições religiosas) e na escola. A importância dada pelo próprio autor à obra em estudo, que parece ter merecido especial cuidado da sua parte, evidencia-se pelo fato de ele tê-la submetido à leitura de 
diversos amigos e intelectuais. Um desses colaboradores, o intelectual Joaquim Hübnr, realizou minuciosa análise da obra, elaborando um parecer extremamente negativo:

considero que a maioria das pessoas ficará irritada com a discrepância entre o título, demasiado penhorante, e todo o restante da obra. De fato, está tão distante de ensinar a arte de ensinar a todos que até o momento sequer me pareceu estar definido o que significa realmente ensinar, e o que difere o ensino de outras ações que, sobretudo por meio da palavra, são exercidas em proveito do homem pelo homem. Muito menos foi mostrado de que modo alguém da melhor maneira possível algo a alguém (COMENIUS, 2011, p. 5-7).

Joaquim Hübnr entende que a obra reduz a arte de ensinar apenas às escolas, reservando aos pais e governantes apenas o papel de apoiá-la em suas ações. Reprova o que ele considera limitação do ato de ensinar aos docentes, esquecendo-se das leis que regem as escolas e das próprias condições nelas existentes para que o ensino aconteça de forma satisfatória. Critica ainda o fato de o autor apresentar diversos preceitos cristãos que, para os seguidores dessa religião, seria algo conhecido, de fácil entendimento e plena aceitação; mas para alcançar outros povos, estranhos ao meio cristão, tais preceitos deveriam ter sido objetos de consistente argumentação. A dura crítica por parte desse examinador, fez Comenius adiar a publicação da obra por, aproximadamente, vinte anos. Continuou, porém, a sua relação de amizade e colaboração com o seu crítico mais severo. Quando decidiu publicar a obra, escreveu uma veemente defesa do seu conteúdo, respondendo inclusive, críticas de Hübner. Sem contestá-lo, quanto à pertinência das observações, explicou os motivos de ter adotado métodos e elaborado os conteúdos, da forma reprovada pelo amigo. Justifica ter apresentado princípios fundamentais que, para os eruditos, talvez, sejam considerados desnecessários; mas, para os iniciantes, indoutos, tais princípios seriam de grande utilidade, para que pudessem ter uma compreensão dos temas específicos da arte de ensinar:

Que a Didática Magna comece pelo fim último do homem e que, incitando-o ao desejo da suprema perfeição, o conduza por todos os graus intermediários até à suprema fruição do seu desejo. E nesses fins universais que se fundamentam os meios universais e os fins de uma reforma perfeita na escola (caps. 8,9,10,11,12): aqui também não vou mudar nada, pois a verdade não mo permite (COMENIUS, 2011, p. 8,9).

O objetivo da obra é exposto logo no início, esclarecendo o que o autor entende como "arte universal de ensinar tudo a todos": O modo certo e excelente para criar, em todas as comunidades, cidades ou vilarejos de qualquer reino cristão, escolas tais, que a juventude dos dois sexos, sem excluir ninguém, possa receber uma formação em letras, ser aprimorada 


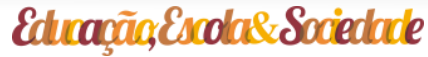

nos costumes, educada para a piedade e, assim, nos anos da primeira juventude, receba a instrução sobre tudo o que é da vida presente e futura, de maneira sintética, agradável e sólida

Lopes (2006) observa que, embora a "Didática Magna” tenha alcançado horizontes mais amplos, os objetivos iniciais da sua escrita era a reconstrução da nação tcheca. Comenius entendia que a educação era o principal meio pelo qual aquele povo poderia se reestabelecer, unido e forte.

\section{O conceito de "Cosmovisão Cristãa"}

De acordo com Souza (2006), o conceito “cosmovisão" surgiu, provavelmente, em Immanuel Kant (1724-1804), quando utilizou na sua Crítica do Juízo (1790) o termo Weltanschauung (Welt - mundo - e Anschauung - percepção). Posteriormente, o conceito foi ampliado e desenvolvido pelos idealistas alemães, e pela tradição romântica destacandose entre eles4 1. Johann G. Fichte (1762-1814), que o utilizou como “a percepção do mundo que Deus possui ao observar a unidade sem distinções dos domínios natural e moral", expostos em Kant; Wilhelm Schelling (1755-1854), que o utilizou como "uma forma autoconcluída, tanto produtiva quanto consciente, de apreender e interpretar o universo dos seres"; George Wilhelm Friedrich Hegel (1770-1831), que o utilizou como "a forma de uma nação, etnia ou indivíduo enxergar o mundo em contextos históricos e geográficos específicos"; Sören Kierkegaard (1813 - 1855) utilizava o termo para designar uma "visão da vida", "uma reflexão existencial sobre o sentido da experiência individual e sua articulação em uma visão coerente da realidade"; e Wilhelm Dilthey (1833-1911) foi um dos principais defensores da Weltanschauung. Para ele, "uma cosmovisão verdadeira seria uma intuição que emerge basicamente do estar-no-meio-da-vida, pois esta é um enigma que exige explicação”. O conceito foi assumido pelos cristãos, depois de certo tempo para, basicamente, definir uma visão de mundo, uma compreensão integral da vida a partir de pressupostos básicos e fundamentais.

James Sire (2018) aponta oito perguntas fundamentais que revelam uma cosmovisão. São fundamentais para definir o que se pensa sobre o que de fato é essencial.

a) O que é realmente verdadeiro? A resposta a essa pergunta trata da realidade primordial e define o que apresentamos como existência última: Deus, deuses, o cosmo material etc.

b) Qual a natureza da realidade externa, do mundo ao nosso redor? A resposta nesse 


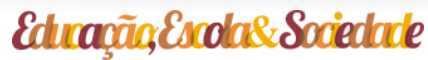

caso define o mundo como criado ou autônomo, caótico ou ordenado, matéria ou espírito.

c) O que é um ser humano? Nesse caso, o objetivo é responder se somos máquinas complexas, deuses adormecidos, descendentes de primatas ou seres criados por um Deus pessoal.

d) $\mathrm{O}$ que acontece quando uma pessoa morre? Somos extintos ou transformados em outro estado; reencarnamos ou somos destinados para outros lugares do universo.

e) Por que é possível conhecer alguma coisa? O que é a consciência e a racionalidade, e se somos realmente conscientes do que conhecemos.

f) Como sabemos o certo e o errado? Há moralidade absoluta ou apenas relativa; valores são historicamente construídos ou revelados; contingentes ou necessários.

g) Qual o significado da história humana? Há propósito na vida humana ou não.

h) Que compromissos centrais, pessoais e que guiam a vida são consistentes com essa cosmovisão? Seria perceber o potencial pessoal, viver um mundo de paz interior, diverso, ou viver para a glória de Deus.

Todas essas perguntas apontadas por Sire (2018) têm a ver com o problema do conhecimento, da epistemologia, e dos conceitos do ser, a metafísica. Tanto a forma de conhecer como o que conhecer são fundamentais na percepção da realidade. $O$ conhecimento é construído ou apreendido a partir de algo que já exista e é revelado? Se for construído, significa que ele não existia antes, mas é produto da sedimentação dos conhecimentos do próprio homem? Se o conhecimento é apreendido de algo que já existia, significa que existe um conhecimento prévio que fornece as fontes e que pode ser encontrado? Por exemplo, se o cristão crê que Deus criou todas as coisas, ele deve crer que Deus também revelou seu próprio ser em todas as coisas, porque nada pode ser criado fora dele. Parece ter sido exatamente essa a ideia do apóstolo Paulo ao afirmar, em sua carta aos Colossenses (1.15-17), sobre Cristo:

Ele é a imagem do Deus invisível, o primogênito de toda a criação; pois, nele foram criadas todas as coisas, nos céus e sobre a terra, as visíveis e as invisíveis, sejam tronos, sejam soberanias, quer principados, quer potestades. Tudo foi criado por meio dele e para ele. Nele, tudo subsiste.

O apóstolo João (1.3) também demonstrou a mesma convicção, ao declarar, em sua narrativa do evangelho, que "todas as coisas foram feitas por intermédio dele, e, sem ele, nada do que foi feito se fez". 
Uma cosmovisão cristã (ou podemos denominar também teorreferência) ${ }^{1}$ é uma maneira de ver o mundo - biblicamente orientada - em relação a todas as estruturas sociais, culturais, econômicas, científicas, religiosas etc. Segundo Nancy Pearcey (2006, p. 37), significa que “"Pensar cristãmente' compreende que o todo da realidade, trata-se de uma perspectiva para interpretar todos os assuntos da vida." Nicodemus $(2019$, p. 17,18) sintetiza:

Todos nós enxergamos a vida através de lentes que são formadas por nossas experiências, nossos pressupostos e, acima de tudo, por nossas crenças [...] A cosmovisão é uma maneira de ver o mundo de acordo com aquilo que se crê

Uma cosmovisão cristã é, portanto, a compreensão de que "ao SENHOR pertence a terra e tudo é que nela se contém, o mundo e o que nele habitam" (Salmo 24.1). Foi esta compreensão que levou Abraham Kuyper (1837 - 1920), em sua aula inaugural, na fundação da Universidade Livre de Amsterdam, a afirmar que "não há nem um centímetro em toda a área da existência humana da qual Cristo, o soberano de tudo, não proclame: 'Isso é meu”' (Apud VAN TILL, 2010, p.139).

\section{Cosmovisão Cristã na Didática Magna, de Comenius}

Como as convicções cristãs influenciaram as propostas da Didática Magna, de Comenius? Quem é o homem? Qual o sentido da vida? Qual a origem da natureza? Como o homem deve se relacionar com ela? Quais os objetivos da educação? A obra discute a educação em uma perspectiva antropológica cristã. $\mathrm{O}$ autor, em harmonia com o pensamento protestante, considera os objetivos da vida humana e suas potencialidades, para a glória de Deus neste mundo, preparando-se para a eternidade:

É evidente que o fim último do homem é a eterna bem-aventurança com Deus; os fins subordinados e úteis a esta vida transitória, por outro lado, são evidenciados pela deliberação de Deus quando estava para fazer o homem: façamos o homem à nossa imagem e semelhança, para que domine sobre os peixes do mar, sobre as aves do céu, sobre os animais da terra e sobre os répteis que se movem sobre ela (Gn 1.26). A partir daí

\footnotetext{
${ }^{1}$ O termo teorreferência foi cunhado por Davi Charles Gomes e significa a ideia de que "Deus é o referencial único para tudo. Não é apenas central a tudo o que existe. É mais do que isso: tudo o que existe, existe em referência a Deus. Todas as coisas têm origem nele, nele subsistem e são para ele" (Cf. GOMES, 2013, p.39). Gomes esclarece que o conceito parte de uma concepção da "tradição reformada de considerar que a realidade tem o seu significado final coram deo." (GOMES, 2006, p. 116, nota 14). Oliveira (2008, p. 31, nota 1) ainda esclarece que a teorreferência pode ser "negativa" ou "positiva": "A teorreferência negativa, como é qualificada a existência do homem em constante apostasia, se dá sempre como forma de emancipação em relação a Deus e rebelião contra a sua Palavra. A teorreferência positiva indica a existência e a apreensão da realidade no interior de um contexto de significado redentivo ou biblicamente orientado. A teorreferência (negativa ou positiva) é a
} 
parece evidente que o homem foi colocado entre as criaturas visíveis para que fosse: I- uma criatura racional; uma criatura senhora das outras criaturas; uma criatura feita à imagem do seu criador e para o seu deleite (COMENIUS, 2011, p.53).

Esta perspectiva é denominada "ascetismo intramundano" (WEBER, 2004). Na Didática Magna, Comenius parte do pressuposto de que o homem foi criado à imagem e semelhança de Deus. Isso significa que no homem estão reunidas amostras dos atributos divinos, tais como: espiritualidade, amor, racionalidade, inteligência, criatividade, sabedoria, dentre outros. O homem é considerado a coroa da criação. Comenius observa:

no homem foram reunidos todos os elementos materiais e todas as formas e seus graus, para exprimir a arte da divina sabedoria [...] Ser racional significa ser capaz de indagar, de dar nomes às coisas e classificá-las; isto é, conhecer, poder designar e entender todas as coisas do mundo, como é evidente no Gênese (COMENIUS, 2011, p. 21,53,54).

A natureza humana é, portanto, privilegiada, tendo grande potencial a ser desenvolvido. Esse potencial, entretanto, segundo a cosmovisão cristã, pela qual Comenius analisa o homem, foi prejudicado pela entrada do pecado no mundo. Com a queda, o homem não deixou de ser a imagem e semelhança de Deus, mas essa imagem foi ofuscada, afetando o homem e suas relações com o próprio Deus, consigo mesmo, com o próximo e com a natureza. Embora tendo em si "as raízes de toda a harmonia", a sua natureza decaída o faz distanciar-se das virtudes e das ações proveitosas para si mesmo e para o próximo. Até as mentes mais brilhantes, se não forem adequadamente preparadas, se desencaminharão em inutilidades perniciosas (COMENIUS, 2011, p. 22, 23, 65, 75). Comenius, fundamentandose no ensino bíblico, na mesma linha hermenêutica de Agostinho, Martinho Lutero e João Calvino, entende que Deus não deixou o homem caído, mas providenciou a sua redenção:

Contudo, ergam-se eternas glórias, louvores, homenagens e bênçãos ao nosso Deus misericordioso que, mesmo nos tendo abandonado por um momento, não nos abandonou na solidão eterna: ao contrário, manifestando a sua Sabedoria, através da qual foram fundados os céus, a terra e todas as coisas, fortaleceu com misericórdia o seu paraíso abandonado, o gênero humano [...] Portanto, de novo verdeja o jardim da Igreja, delícia do coração divino [...] (COMENIUS, 2011, p. 23).

Essa renovação, entretanto, segundo ele, não é imediata e nem alcança todas as pessoas da mesma forma, ao mesmo tempo e intensidade. Nesse ponto é que Comenius exalta o poder da educação como instrumento de Deus para renovar a humanidade caída, devendo ser esse o esforço dos redimidos, promovendo a redenção dos outros: "não há 
caminho mais eficaz para corrigir a corrupção humana que a correta educação da juventude" (COMENIUS, 2011, p. 27). Por meio da educação é que o homem seria continuamente aproximado do seu estado original de perfeição. O objetivo da educação é "tornar os homens sábios na mente, prudentes na ação e piedosos no coração" (COMENIUS, 2011, p. 96). Embora a condição original não possa ser alcançada nesta vida, o seu aperfeiçoamento deve ser buscado continuamente. Comenius cita Vives e Sêneca, que expressam pensamentos semelhantes (COMENIUS, 2011, p. 57). Fala sobre o entendimento de Vives, de que o cristão é o homem restituído à sua natureza, devolvido à sua condição original, pela redenção em Cristo. Sêneca, semelhantemente, entende que a essência da sabedoria é retornar ao lugar de onde o erro público do homem o expulsou. Nessa perspectiva, educar é humanizar, pois o sentido da vida está em satisfazer ao Criador:

O homem para ser homem, precisa ser formado [...] Vimos que a natureza dá as sementes da ciência, da honestidade, da religião, mas não dá a virtude, a religião; estas são adquiridas com a prece, com o estudo, com o esforço pessoal [...] que ninguém cuide ser realmente homem se não tiver aprendido a comportar-se como homem, ou seja, se não tiver sido formado nas coisas que o fazem o homem [...] o homem, por ser dotado de corpo, é feito para trabalhar, e no entanto vemos que não tem de nascença nada mais do que simples aptidão: será preciso ensiná-lo aos poucos a sentar-se, a ficar ereto, a andar, a mexer as mãos para realizar uma operação. Como, então, a nossa mente poderia ter a prerrogativa de ser perfeita, em si e por si, sem preparação? É lei para todas as criaturas ter início do nada e desenvolver-se gradualmente, seja quanto à essência, seja quanto às ações (COMENIUS, 2011, p. 71-73)

Essa concepção de homem leva à conclusão necessária de que a educação deve ser para todos: "ensinar tudo, a todos". Toda a realidade criada por Deus deve ser conhecida por todo o gênero humano. Remete aos inflamados discursos de Martinho Lutero, no século XVI, solicitando às autoridades que fossem criadas escolas (Cf. NUNES,2017). Denuncia a inexistência da quantidade suficiente de escolas e a exclusão ao seu acesso:

Não é em todas as comunidades menores, aldeias e vilarejos que se encontram escolas. E onde as há, não se destinam a todos indistintamente, mas apenas a alguns, aos mais ricos: por serem caras, os mais pobres não são admitidos, a não ser, às vezes, por acaso ou por beneficência de alguém. Por isso, é provável que muitos excelentes engenhos vivam e morram sem instrução, com grave prejuízo para a Igreja e para os Estados (COMENIUS, 2011, p. 104).

Entendendo que "na natureza se encontra um antídoto para cada mal” (2011, p.119), Comenius entende que, mesmo as pessoas mais problemáticas não deveriam ser excluídas da educação, pois poderiam ser corrigidas, tornando-se valorosos para a sociedade e para a 
glória do Criador. Até os que ele chama de "preguiçosos, obtusos e idiotas" deveriam ser educados com prudência e paciência. Argumenta, citando Plutarco: "Não está em poder de ninguém a qualidade dos filhos que nascem, mas está em nosso poder obrar de tal modo que se saiam bem com uma educação correta" (COMENIUS, 2011, p. 120).

devem ser confiados à escola não só os filhos dos ricos ou pessoas mais importantes, mas todos em igualdade, de estirpe nobre ou comum, ricos e pobres, meninos e meninas, em todas as cidades, aldeias, povoados, vilarejos [...] todo o homem nasceu para o mesmo fim principal, o de ser homem, ou seja, criatura racional, senhora das outras criaturas, imagem manifesta do seu Criador. Portanto, todos quantos forem devidamente instruídos nas letras, nas virtudes e na religião devem se tornar capazes de levar a vida presente de modo útil e de preparar-se dignamente. Deus mesmo nos garante, com mil exemplos, que ninguém é privilegiado perante ele. Portanto, se permitirmos que apenas alguns aprimorem seu talento, excluindo todos os outros, estaremos ofendendo não só nossos irmãos naturais, mas a Deus mesmo, que deseja ser conhecido, amado e louvado por todos aqueles aos quais imprimiu a sua imagem [...]. Além disso, não sabemos o fim a que cada homem foi destinado pela divina providência. Sabe-se que mais de uma vez, Deus fez das pessoas mais pobres, mais abjetas, mais obscuras, excelentes instrumentos da sua glória. Por isso, cabe-nos imitar o sol celeste, que ilumina, aquece e vivifica toda a terra, para que toda criatura que possa viver, verdejar, florescer e dar frutos viva, verdeje, floresça e dê frutos" (COMENIUS, 2011, p. 89).

Comenius antecipa aos argumentos de que os "lerdos", "retardados", não merecem esforços para a educação. Cita um adágio popular: "o trabalho obstinado tudo vence”. Afinal, "apraz-nos ter nos pomares não só árvores que deem frutos precoces, mas também as que deem frutos de fim de estação" (COMENIUS, 2011, p. 90, 91).

Nessa mesma linha de argumentação, Comenius dedica espaço especial em sua obra para afirmar a pertinência da inclusão das mulheres na busca do conhecimento de todas as coisas, para a glória de Deus, seu Criador. Na narrativa da criação, homem e mulher foram criados à imagem e semelhança de Deus. Essencialmente iguais, portanto. Assim, o acesso ao conhecimento não deveria ser negado às mulheres. Mesmo o leitor que, de forma anacrônica, reprove termos ou expressões por ele utilizados, considerando-os inadequados, concordará que as suas ideias eram "avançadas" no que concerne à igualdade dos sexos, especificamente quanto ao acesso à educação escolar:

Também às mulheres assim como os homens, são imagem de Deus, participam da graça divina e do reino do século futuro; também são dotadas de inteligência aguçadas e aptas ao saber (frequentemente mais que nosso sexo); também para elas, como para os homens, estão abertas as portas de postos elevados, porque muitas vezes foram destinadas por Deus ao governo dos povos, a aconselhar sabiamente reis e príncipes, à 
ciência médica e às outras ciências úteis ao gênero humano, bem como ao dom da profecia e a censurar sacerdotes e bispos. Por que então permitimos que alfabetizem e depois as afastamos dos livros? Temos medo da sua falta de reflexão? Mas quanto mais ocupada estiver a mente, menor será o espaço destinado à imprudência, que nasce de mentes vazias. Portanto, as mulheres também devem ser instruídas, não certamente, por meio de uma mistura indiscriminada de livros (de resto, isso vale também para o outro sexo; aliás, é deplorável que até o momento não se tenha agido com mais cautela), mas por meio dos livros que permitam adquirir para sempre virtudes verdadeiras e verdadeira piedade, com o verdadeiro conhecimento de Deus e de suas obras (COMENIUS, 2011, p. 91 ).

Embora reconhecendo que a educação geral dos filhos é responsabilidade intransferível dos pais, faz veemente apologia das escolas que, para ele, são de fundamental necessidade. Afinal, nem todos os pais teriam os conhecimentos necessários para a instrução dos filhos nas diversas ciências. Mesmo aqueles que dispusessem de tal conhecimento abrangente, certamente teriam dificuldades em dedicar tempo a essa instrução. As escolas são, portanto, indispensáveis. Para ele, “as escolas são as oficinas da humanidade; elas transformam os homens em homens de verdade" (COMENIUS, 2011, p. 96). Acrescenta:

\begin{abstract}
Demostrado que a pequena planta do Paraíso, a juventude cristã, não pode crescer desregradamente, mas precisa de muitos cuidados, resta ver quem deve assumir essa responsabilidade. Ela cabe, naturalmente, aos pais, que, tendo sido autores da vida, devem ser autores também da vida intelectual, moral e religiosa [...] No entanto, como tanto os homens quanto as questões humanas se multiplicam, raros são os pais que sabem ou podem educar os filhos e que tem tempo suficiente para isso: felizmente, já há tempos firmou-se o hábito de confiar muitos filhos em conjunto a pessoas escolhidas para instruí-los, pessoas eminentes pela cultura, pela austeridade dos costumes. Esses educadores são chamados preceptores, pedagogos, mestres e professores: os locais destinados a esse ensino comum são chamados escolas, institutos, auditórios, colégios, ginásios, academias, etc.
\end{abstract}

Essa afirmação remete a temas atuais tais como os referentes à relação família e escola, Home Schooling, competências e saberes necessários ao exercício da profissão docente, dentre outros. Serve também para fundamentar estudos de história das instituições escolares, apontando para a escola no imaginário social europeu do século XVII, tendo a cosmovisão cristã como pano de fundo. O conhecimento da realidade criada e entregue ao domínio do homem é necessário para agradar ao Criador. É dever cristão promover o conhecimento para si mesmo e para todas as pessoas. As escolas, promotoras de conhecimento e de sabedoria, são instituições que humanizam

as escolas são oficinas da humanidade; elas transformam os homens em homens de verdade, ou seja (visando aos fins já estabelecidos): 1) uma 
criatura racional; 2) uma criatura senhora das criaturas (inclusive de si mesma); 3) uma criatura deleite do seu criador. Isso acontecerá se as escolas se esforçarem por tornar os homens sábios na mente, prudentes nas ações, piedosos no coração (COMENIUS, 2011, p. 96).

A busca dinâmica da compreensão da complexa realidade é a forma sábia de aproveitar o tempo sobre a terra. Contrapondo-se aos lamentos de Aristóteles e Hipócrates no que concerne à brevidade da vida, Comenius concorda com Sêneca, que afirmou que "a vida para quem sabe utilizá-la é longa". Entende que aproveitando bem o tempo, ela será suficiente para realização de obras importantes. Deve-se dedicar à busca e à promoção do conhecimento sobre "todas as coisas", respeitando "a diversidade de engenhos", as aptidões individuais. Para isso, a formação geral do homem pela família e para o conhecimento mais amplo e mais profundo nas escolas devem visar o homem completo:

as escolas ao formarem um homem, formem-no de maneira completa, para torná-lo apto aos compromissos desta vida e à eternidade para a qual tendem todas as coisas deste mundo. Por isso, nas escolas deverão ser ensinadas não só as letras, mas também a moral e a piedade. As letras refinam o intelecto, a língua e a mão do homem, para que ele possa contemplar, falar e obrar de modo racional em todas as coisas úteis. Se for esquecida uma dessas funções, haverá um hiato que não só será pernicioso para a instrução, mas também será capaz de infirmar a solidez do processo educativo. Porque nada pode ser sólido se não for coerente em todas as suas partes (COMENIUS, 2011, p. 186).

A educação, pelos pais, desde à mais tenra idade, e, posteriormente, com o auxílio da escola, deve direcionar as novas gerações para as "virtudes cardeais": a prudência, a temperança, a fortaleza e a justiça (COMENIUS, 2011, p. 264). A pessoa que não reúne tais virtudes é por ele considerada um edifício sem alicerces. Ao discorrer detalhadamente sobre essas virtudes fundamentais que devem ser objeto da educação, afirma: "A prudência deve ser adquirida por uma boa educação, aprendendo-se as verdadeiras diferenças e o valor das coisas. O juízo correto acerca das coisas é o fundamento de todas as virtudes" (COMENIUS, 2011, p. 264). Nesse sentido, novamente, cita Vives:

A verdadeira sabedoria consiste em julgar as coisas com exatidão, ou seja, avaliar cada uma como realmente é; em não ir à cata de coisas vis como se fossem preciosas; em não jogar fora as preciosas, como se fossem vis; em não censurar as coisas louváveis e em não louvar as censuráveis. Disto nascem todos os erros nas mentes dos homens e todos os vícios; e na vida humana não há nada de mais pernicioso que julgar mal, porque não se dá às coisas o seu justo valor. Que o homem, pois, se habitue, desde pequeno, a ter opiniões exatas sobre as coisas, que devem crescer juntamente com a idade. E que se apegue às boas, fugindo das ruins, para que nele o hábito de agir bem se torne natural (VIVES, apud. COMENIUS, 2011, p. 264). 


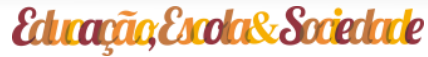

A temperança (moderação) é a primeira das "virtudes cardeais". Segundo Comenius, os jovens jamais deveriam se esquecer da "regra de ouro" que deveria discipliná-los em tudo: "nada em excesso". Moderação no comer e beber, no sono, no trabalho, nas recreações, no falar e no calar. Essa temperança deveria ser objeto da educação desde à infância para que se tornassem hábito para toda a vida. Essa disciplina, moderação, temperança, entretanto, deveria ser ensinada e praticada de forma dócil, prazerosa para que, como os demais conteúdos e comportamentos, seja eficazmente aprendida. Sobre o prejuízo que os excessos podem causar às pessoas, afirma: "é preciso parar sempre, antes da saciedade e do tédio" (COMENIUS, 2011, p. 265). Moderação, sensatez, prudência, são conceitos amplamente ensinados no texto sagrado dos cristãos, tão caro a Comenius.

A fortaleza, a segunda virtude cardeal, está bem articulada com a primeira. Educar para que a pessoa se torne "forte". Para ele, significa, principalmente, desenvolver a capacidade do homem para dominar-se a si mesmo. O "domínio próprio" que, no ensino bíblico, é o fundamento da doutrina cristã em geral, é "fruto do Espírito Santo". Evidência da ação de Deus no indivíduo que a ele se entrega pela fé. Comenius (2011, p. 265) afirma:

\footnotetext{
Para adquirir fortaleza é preciso vencer-se a si mesmo; cumpre moderar a vontade de vagabundear e de divertir-se muito e além do justo; e deve frear-se a impaciência, o descontentamento, a ira. Na base disto está o hábito de agir segundo a razão, e não por paixão ou impulso. O homem é um animal racional: deve habituar-se a ser guiado pela razão, perguntandose sempre, ao agir, o que, por que e como fazer corretamente as coisas. Isso para que o homem seja realmente dono de suas ações.
}

Considerando o ensino bíblico de que "a criança entregue a si mesma envergonhará a sua mãe" (PROVÉRBIOS, 29.15), propõe a disciplina moderada para promover a moderação, para que, por meio de palavras, exemplos, atos e correções, a criança seja fortalecida, para dominar a sua própria vontade, quando essa a compele ao erro ou às situações de perigo. Aprendendo a obedecer aos seus superiores, pais, mestres e autoridades em geral, a criança aprenderá a dominar a sua própria vontade, administrando-a, sabiamente. Dominando os seus próprios impulsos, as crianças serão dóceis umas com as outras, mesmo em situações de conflito, o que poderá produzir frutos permanentes em seu caráter. Agindo, segundo a razão, e, não pelos impulsos. Agindo assim, conscientemente, o homem se torna “dono das suas próprias ações".

A terceira virtude cardeal, segundo Comenius (2011, p. 265), é a justiça: “Que aos homens aprendam a justiça sem prejudicar ninguém, dando cada um o que lhe pertence, fugindo da mentira e do engodo, e mostrando-se sempre laboriosos e amáveis”. Essa virtude, 
manifesta-se nas relações humanas e no trabalho. Quem nela é instruído de forma eficaz, saberá relacionar-se com franqueza e honestidade com as outras pessoas e será também dedicada ao trabalho, suportando todo tipo de trabalho justo, evitando tornar-se um "peso inútil”. O pensamento de Comenius alinha-se com a ideia de vocação, ensinada pelos reformadores protestantes do século XVI, e pelo protestantismo em geral, explorada por Weber (2004), para compreender a ética protestante e os seus impactos sociais.

\begin{abstract}
Virtude relacionada com a justiça é o prazer e a presteza em ajudar os outros: esta deve estar entre as primeiras instiladas nos jovens. $\mathrm{O}$ triste vício do egoísmo ( $\Phi$ i $\lambda \alpha \nu \tau i \alpha)$ é estritamente relacionado com a natureza corrupta que faz desejar apenas o proveito próprio, sem atentar os outros; é fonte de contínuas e múltiplas confusões nas ações humanas, pois cada um se preocupa consigo mesmo e continua indiferente ao bem público; por isso deve-se inculcar bem nos últimos a finalidade da nossa vida, qual seja, não se nasce apenas para si mesmo, mas para Deus e para o próximo (COMENIUS, 2011, p. 267)
\end{abstract}

Educar para a justiça, desenvolvendo a honestidade nos relacionamentos, segundo Comenius, requer cuidado com as companhias, devendo evitar as más e buscar as boas, e observação constante, tanto na família, desde muito cedo como na escola. Cita como exemplo a educação dada por Aristóteles a Alexandre e seus resultados (COMENIUS, 2011, p. 266). A justiça no trabalho é adquirida mediante treinamento prático em atividades "sérias e agradáveis". Afinal, "a virtude cultiva-se com fatos, e não com palavras" (COMENIUS 2011, p. 266). Aqui, como na Didática Magna em geral, expressa-se a "pedagogia realista" (Cf. ARANHA,2006), própria do século XVII, o “século do método”. Insiste no conceito de que "a formação da virtude deve iniciar-se na mais tenra idade, antes que os espíritos contraiam vícios" (COMENIUS, 2011, p. 268).

As virtudes devem ser cultivadas, partindo do pressuposto de que o homem foi criado por Deus, para a sua própria glória. A prática do amor a Deus e ao próximo constituise no cerne do sentido da vida. Para que todas essas virtudes sejam cultivadas, é necessário a "educação para a piedade", assim por ele conceituada:

A piedade é um dom de Deus; é dada a nós pelo céu, por obra e virtude do Espírito Santo que, no entanto, age ordinariamente por meios comuns e elege como ministros os pais, os preceptores e os ministros da igreja, que plantam e irrigam com cuidado e atenção os renovos do paraíso. Por isso é justo que eles entendam a razão de seus deveres. Já dissemos o que piedade significa para nós: é o nosso coração, impregnado pelo reto sentimento, sabendo buscar a Deus em toda parte [...] procuramos Deus

\footnotetext{
2 Piedade é usada por Comenius no sentido de dedicação sincera a Deus, remetendo-se no termo grego, bíblico “eusebeia” que significa adoração, consagração, religião verdadeira (Cf. BARCLAY, 1985, p.73)
} 
notando os sinais na divindade em tudo o que é criado [...] As fontes são as Sagradas Escrituras, o mundo e nós mesmos, ou seja, a palavra de Deus, suas obras e nosso sentimento interior (COMENIUS, 2011, p. 271,272).

A proposta de "ensinar tudo a todos" está, portanto, alicerçada na convicção de que o homem é uma criatura especial, "imagem e semelhança de Deus". A sua responsabilidade é dominar, cultivar e guardar as demais obras criadas. Deve fazer isso de acordo com as orientações do Criador e Senhor, nas Escrituras.

\section{Considerações finais}

O pensamento educacional de Comenius está fundamentado nas convicções cristãs articuladas ao seu contexto, ao espírito do século XVII. A educação é compreendida por ele de forma "científica". Entendia o conhecimento da realidade como vocação divina para a promoção da vida, respeitada a diversidade de vocações. Enfatizava a necessidade da criação de escolas para todos, com métodos que tornassem o processo de ensino e aprendizagem prazeroso, contrapondo-se aos modelos medievais. Esses princípios são expressados, desde os reformadores protestantes e de outros humanistas desse período. Comenius destaca-se, entretanto, pela sistematização dessas ideias e pela produção de uma obra específica sobre o tema. O seu estudo é de grande relevância para a formação de professores e para pesquisadores dessa área do conhecimento. Este estudo introdutório teve como objetivo demonstrar como a educação é considerada por Comenius um recurso fundamental para que o indivíduo seja preparado para, na perspectiva da análise de Max Weber (2004), enfrentar o mundo com o objetivo de transformá-lo, segundo os fundamentos da ética cristã protestante. Espera-se que este estudo introdutório, além dos seus objetivos específicos, motive outras abordagens, ampliando o debate.

\section{Referências}

ALVES, Vânia Maria; WALDOW, Carmen. A Importância do Estudo dos Clássicos para Pensar a Educação: Antigas questões, novos desafios para a formação de professores. In: Notandum, Ano 23, n. 58, 2020.

ALVES, Vânia Maria; WALDOW, Carmen. O Estudo dos Clássicos Para Pensar a Educação: Antigas Questões, Novos Desafios para a Formação Docente. In: Notandum. n. 52(23). Maringá-PR: UEM, 2019.

ARANHA, Maria Lúcia Arruda. História da educação e da pedagogia. 3. ed. São Paulo: Moderna, 2006. 
BARCLAY, William. Palavras chaves do Novo Testamento. São Paulo: Vida Nova, 1985.

CAMBI, Franco. História da pedagogia. São Paulo: UNESP, 1999.

CARVALHO, Guilherme Vilela de; CUNHA, Maurício José Silva. Cosmovisão cristã e transformação: espiritualidade, razão e ordem social. Viçosa: Ultimato, 2006.

COMENIUS, João Amós. Didática Magna: a arte de ensinar tudo a todos. 4. ed. São Paulo: Martins Fontes, 2011.

FOUCAULT, Michel. O que é um autor? Lisboa: Passagens, 1992.

GADOTTI, Moacir. Histórias das ideias pedagógicas. São Paulo: Ática, 2002.

GASPARIN, J. L. Comenius e a emergência da modernidade na educação. Petrópolis-RJ: Vozes, 1997.

GASPARIN, João Luiz. Os clássicos na formacão de professores: um retorno necessário em tempos de crise. Curitiba-PR: CRV, 2019.

GOHEEN, Michael W. Introdução à Cosmovisão Cristãa vivendo na intersecção entre a visão bíblica e a contemporânea. Vida Nova: São Paulo: 2016.

GOMES, Davi Charles. A Metapsicologia Vantiliana: uma incursão preliminar. In: Fides Reformata XI:1 (2006), p. 116, nota 14.)

GOMES, Wadislau Martins. Todo mundo pensa, você também: Aprendendo a pensar biblicamente. Brasília: Monergismo, 2013.

GONTIJO, Fábio de Brito. A Didática Magna de Comenius e Declarações da UNESCO: Educação para todos - a inspiração de Comenius e a posição da UNESCO. Uberaba-MG: Universidade de Uberaba, 2016 (Dissertação de Mestrado)

HOYKAAS, Ruy. A Religião e o desenvolvimento da Ciência Moderna. Brasília-DF: UNB, 1988.

LEITE, Cláudio A. C.; CARVALHO, Guilherme Vilela de; CUNHA, Maurício José Silva. Cosmovisão cristã e transformação: espiritualidade, razão e ordem social. Viçosa: Ultimato, 2006, p.39-55.

LOPES, Edson Pereira. A inter-relação da Teologia com a Pedagogia no pensamento de Comenius. São Paulo: Mackenzie, 2006.

LOPES, Edson Pereira. Espiritualidade Protestante no Pensamento de João Amós Comenius. In: Pistis \& Praxis. n. 1. 2013.

MATOS, Alderi Souza de. A caminhada cristã na história: A bíblia, a igreja e a sociedade ontem e hoje. Viçosa-MG: Ultimato, 2005.

NICODEMUS, Augustus. Cristianismo na Universidade. São Paulo: Vida Nova, 2019.

NUNES, César. Ide ensinai tudo a todos: 500 anos da Pedagogia Luterana. Porto Alegre-RS: Concórdia, 2017.

OLIVEIRA, F. A. Reflexões críticas sobre Weltanschauung: uma análise do processo de 
formação e compartilhamento de cosmovisões numa perspectiva teo-referente. In: Fides Reformata XIII:1 (2008), p. 31, nota 1.)

PEARCEY, Nancy R.; THAXTON, Charles B. A alma da ciência: Fé Cristã e Filosofia Nagtural. São Paulo: Cultura Cristã, 2005.

PEARCEY, Nancy. Verdade absoluta: libertando o cristianismo de seu cativeiro cultural. Rio de Janeiro: CPAD, 2006.

PEREIRA, Meira Chaves. Educação e Didática em Comenius. In: Revista de Formación e Inovación Educativa Universitária. v. 9, n. 2. Vigo: Educacion Editora, 2016.

SANTOS, Oscar Marreta dos. As contribuições de Comenius para a formação de professores em nível médio na modalidade normal. In: Cadernos PDE V. II Curitiba-PR : SEE, 2016.

SANTOS, Oscar Marreta dos. Os desafios da escola pública paranaense na perspectiva do professor PDE Produções Didático-Pedagógicas. Curitiba-PR: Secretaria Estadual de Educação, 2016.

SAVIANI, Dermeval. História das ideias pedagógicas no Brasil. 4. ed. Campinas-SP: Autores Associados, 2013.

SILVA, Roge Cavalcanti da; SALDANHA, Gustavo Silva. Uma "impressão históricobibliográfica" sobre Comenius: da cultura à cultura impressa na obra comeniana In CID. Ribeirão Preto, v. 8, n. 1, p. 4-23, mar./ago. 2017.

SIRE, James W. O universo ao lado: Um Catálogo Básico sobre Cosmovisão. 5. Ed. BrasíliaDF: Monergismo, 2018.

SOUZA, Rodolfo Amorim Carlos de. Cosmovisão: evolução do conceito e aplicação cristã. In: LEITE, Cláudio A. C.; CARVALHO, Guilherme Vilela de; CUNHA, Maurício José Silva. Cosmovisão Cristã e Transformação: espiritualidade, razão e ordem social. Viçosa: Ultimato, 2006.

TEIXEIRA, Juliana Cristina; ZANOTELLI, Eduardo José; CARRIERI, Alexandre de Pádua. A Importância dos Clássicos na Formação do Pesquisador: o que nos diz Conceitos de Socialização, Identificação e Campo Intelectual como Campo de Poder. In: Revista de Ciências da Administração. v. 16, n. 38. Florianópolis-SC: UFSC, 2014.

VAN TIL, Henry. O conceito calvinista de cultura. São Paulo: Cultura Cristã, 2010.

WEBER, Max. A ética protestante e o espírito do capitalismo. São Paulo: Companhia das Letras, 2004. 